\title{
Intermolecular Potentials of Argon, Methane, and Ethane $\dagger$
}

\author{
Andrew G. De Rocco and J. O. Halford \\ Department of Chemistry, University of Michigan, Ann Arbor, Michigan
}

(Received February 4, 1958)

\begin{abstract}
The viscosities of argon, methane, and ethane are reported over a temperature range from $\sim 210^{\circ} \mathrm{K}$ to $\sim 45^{\circ} \mathrm{K}$. In conjunction with second virial coefficient data, the viscosities have been employed to estimate the potential parameters for an Exp:6 potential. For the spherically symmetric molecules a single set of parameters served to reproduce the equilibrium and transport properties with serviceable accuracy. For ethane the procedure failed, and this failure was taken as further evidence for the fundamental inadequacy of the assumptions of central forces and elastic collisions.
\end{abstract}

\section{INTRODUCTION}

$\mathbf{R}^{\mathrm{E}}$ ECENTLY considerable attention has been given to the problem of correlating the transport and equilibrium properties of gases in terms of an intermolecular potential energy derived from measured properties of the gases. ${ }^{1}$ Madan, ${ }^{2}$ for example, has used the property of thermal diffusion to estimate the potential parameters for several gases, most recently krypton.

In spite of the lack of convincing evidence to support the claim that the modified Buckingham Exp: 6 potential predicts better than the Lennard-Jones 12:6 potential the properties of gases over extended ranges of measurement, ${ }^{3}$ it has become customary to offer arguments designed to show that the Exp: 6 is physically more realistic and (certainly) more flexible, and, therefore, to present the properties of dilute nonpolar gases in terms of an Exp: 6 potential.

We have measured in some detail the temperature variation of viscosity for argon, methane, and ethane and extracted from these data the potential parameters for the Exp: 6 potential. For the former two gases fairly wide comparison with existing results was possible, ${ }^{2,3}$ for the latter only the 12:6 has been reported. ${ }^{1}$

Ethane in addition presented an interesting case. From the studies of Mason and Rice ${ }^{3}$ it is known that for molecules lacking spherical symmetry the ChapmanEnskog theory fails, and they found for example, that a single set of potential parameters was unsuitable for discussing both the equilibrium and transport properties of nitrogen. This result was generally true as the molecules became more nonspherical, implying high values for the parameter $\alpha, \alpha \geqslant 16$.

On the other hand, treating the calculation of the second virial coefficient for nonspherical molecules as a

$\dagger$ Based on a dissertation submitted in August, 1956, by Andrew G. De Rocco, in partial fulfillment of the requirements for the degree of Doctor of Philosophy.

1 Hirschfelder, Curtiss, and Bird, The Molecular Theory of Gases and Liquids (John Wiley and Sons, Inc., New York, 1954).

2 M. P. Madan, J. Chem. Phys. 23, 763 (1955); B. N. Srivastava and M. P. Madan, ibid. 21, 807 (1953); M. P. Madan, ibid. 27, 113 (1957).

${ }^{8}$ E. A. Mason and W. E. Rice, J. Chem. Phys. 23, 843 (1954). perturbation on the spherical case, ${ }^{4}$ one finds that, at least as far as long-range directional forces are concerned, ethane is more nearly spherically symmetric than nitrogen. The application of the Chapman-Enskog theory to ethane becomes of interest therefore, the question being just how nonspherical a molecule the theory can handle in practice.

\section{DETERMINATION OF POTENTIAL PARAMETERS}

Several methods have been described for estimating potential parameters from experimentally obtained TABLE I. A comparison of the potential parameters by different methods.

\begin{tabular}{|c|c|c|c|c|c|}
\hline Substance & $\alpha$ & $\epsilon / k\left({ }^{\circ} \mathrm{K}\right)$ & $r_{m}(A)$ & Method & $\begin{array}{l}\text { Refer- } \\
\text { ence }\end{array}$ \\
\hline \multirow[t]{2}{*}{ Argon } & $\begin{array}{l}14 \\
14\end{array}$ & $\begin{array}{l}123.0 \\
123.2\end{array}$ & $\begin{array}{l}3.867 \\
3.866\end{array}$ & $\begin{array}{l}\text { Visc. } \\
\text { Vis. 2nd virial, } \\
\text { Crystal }\end{array}$ & $\stackrel{a}{b}$ \\
\hline & $\begin{array}{l}14 \\
14\end{array}$ & $\begin{array}{l}122.46 \\
122.9\end{array}$ & $\begin{array}{l}3.868 \\
3.868\end{array}$ & $\begin{array}{l}\text { Visc. } \\
\text { Thermal diffusion }\end{array}$ & $\begin{array}{l}\mathrm{c} \\
\mathrm{c}\end{array}$ \\
\hline \multirow[t]{2}{*}{ Methane } & $\begin{array}{l}14 \\
14\end{array}$ & $\begin{array}{l}152.4 \\
152.8\end{array}$ & $\begin{array}{l}4.209 \\
4.206\end{array}$ & $\begin{array}{l}\text { Visc. } \\
\text { Visc. 2nd virial, } \\
\text { Crystal }\end{array}$ & $\begin{array}{l}a \\
b\end{array}$ \\
\hline & $\begin{array}{l}14 \\
14\end{array}$ & $\begin{array}{l}152.20 \\
150.6\end{array}$ & $\begin{array}{l}4.203 \\
4.222\end{array}$ & $\begin{array}{l}\text { Visc. } \\
\text { Thermal diffusion }\end{array}$ & in $c$ \\
\hline Ethane & $\begin{array}{l}16 \\
16 \\
(12: 6)\end{array}$ & $\begin{array}{l}229.1 \\
249.5 \\
230 \\
243\end{array}$ & $\begin{array}{l}4.905 \\
5.226 \\
4.418(\sigma) \\
3.954(\sigma)\end{array}$ & $\begin{array}{l}\text { Visc. } \\
\text { 2nd virial } \\
\text { Visc. } \\
\text { 2nd virial }\end{array}$ & $\begin{array}{l}a \\
a \\
d \\
d\end{array}$ \\
\hline
\end{tabular}

Present work

b E. A. Mason and W. E. Rice, J. Chem. Phys. 22, 843 (1954),

- See reference 2.

d See reference 1, p. 1112 .

properties; we have employed the method described in detail by Mason and Rice ${ }^{5}$ in which, for example, the quantities $\log \left[f_{\eta}^{(3)} / \Omega^{(2,2) *}\right]$ are plotted $v s \log T^{*}$ to yield a family of curves depending on the choice of $\alpha$. A plot of the experimental quantities $\log \left[10^{7} \eta /(M T)^{\frac{1}{3}}\right]$ vs $\log T$ may be brought into coincidence with the reduced quantities from which $\epsilon / k, r_{m}$, and $\alpha$ may be obtained. In practice viscosity and virial coefficients are utilized jointly to estimate the parameters, a pro-

\footnotetext{
${ }^{4}$ Castle, Jansen, and Dawson, J. Chem. Phys. 24, 1078 (1956).

${ }^{5}$ E. A. Mason and W. E. Rice, J. Chem. Phys. 22, 522 (1954).
} 
cedure which permits unique assignment of the parameters where some of the data are incomplete.

The parameters $\epsilon, r_{m}$, and $\alpha$ are defined by the Exp: 6 potential:

$$
\varphi(r)=\frac{\epsilon}{1-6 / \alpha}\left[\frac{6}{\alpha} e^{\alpha\left(1-r / r_{m}\right)}-\left(\frac{r_{m}}{r}\right)^{6}\right],
$$

where $\varphi(r)$ represents the potential energy for a separation $r, \epsilon$ is the minimum energy for a separation $r_{m}$, and $\alpha$ is a parameter somehow related to the steepness of the repulsion energy.

Our experimental data were obtained by the method of transpiration. Since this is a standard technique and has been well described in the textbooks ${ }^{6}$ no detailed discussion is included here.*

Table I contains our values for the potential parameters in comparison with previous values.

TABLE II. Comparison of observed viscosities of argon with those calculated for the Exp:6 potential.

\begin{tabular}{llll}
\hline \hline & \multicolumn{2}{c}{$1^{7} \eta \mathrm{g}-\mathrm{cm}^{-1}$-sec-1 } & \\
$T^{\circ} \mathrm{K}$ & Obs & Calc & Obs \\
\hline 210.7 & 1670 & 1675 & \\
250.1 & 1952 & 1948 & $2114^{\mathrm{a}}$ \\
273.16 & 2102 & 2095 & $2212^{\mathrm{a}}$ \\
293.2 & 2220 & 2222 & $2273^{\mathrm{b}}$ \\
300.3 & 2267 & 2270 & \\
311.5 & 2340 & 2339 & \\
320.3 & 2389 & 2392 & \\
328.2 & 2446 & 2440 & \\
337.7 & 2499 & 2495 & \\
343.0 & 2523 & 2528 & \\
353.4 & 2592 & 2588 & \\
368.6 & 2674 & 2670 & \\
381.3 & 2735 & 2740 & \\
396.4 & 2819 & 2822 & \\
409.1 & 2896 & 2890 & \\
423.7 & 2971 & 2967 & \\
438.9 & 3050 & 3046 & \\
448.2 & 3099 & 3094 & \\
461.9 & 3170 & 3163 & \\
471.4 & 3221 & 3216 & \\
\hline \hline
\end{tabular}

a M. Trautz and W. Ludewigs, Ann. Physik 3, 409 (1929).

b H. L. Johnston and E. R. Grilly, J. Phys. Chem. 46, 948 (1942).

\section{COMPARISON WITH EXPERIMENT}

For an adequate potential a single set of potential parameters (in conjunction with correct theories) should be sufficient to completely determine both equilibrium and transport properties. For the inert gases where the theory is certainly adequate, comparison of calculated and observed values for the properties of the system permits a reasonably sensitive discrimination for the potential.

For methane, apart from thermal conductivity, the presence of internal degrees of freedom does not seem to seriously affect the success of the Chapman-Enskog theory in predicting the equilibrium and transport

${ }^{6}$ Partington, An Advanced Treatise on Physical Chemistry (Longmans Green and Company, London, 1949), p. 877.

* The authors' modifications of the method and detailed information on technique and procedure are available upon request. We estimate our accuracy as $\geqslant 0.5 \%$.
TABLE III. Thermal conductivity of argon using potential parameters from viscosity.

\begin{tabular}{ccc}
\hline & $10^{7} \lambda$ cal-cm-1-sec $^{-1}$ Caleg $^{-1}$ & \\
$T^{\circ} \mathrm{K}$ & 145 & Obs \\
\hline 90.2 & 293 & $141^{\mathrm{a}}$ \\
194.7 & 390 & $293^{\mathrm{a}}$ \\
& & $385^{\mathrm{b}}$ \\
273.2 & $590^{\mathrm{a}}$ \\
$394^{\mathrm{a}}$ & $506^{\mathrm{a}}$ \\
373.2 & 505 & $614^{\mathrm{a}}$ \\
491.2 & 618 & $685^{\mathrm{a}}$ \\
579.1 & 690 & \\
\hline
\end{tabular}

W. G. Kammuluik and E. H. Carman, Proc. Roy, Soc. (London) 65B,70 (1952).

b S. Weber, Ann. Physik 54, 323 (1917).

c T. L. Ibbs and A. A. Hirst, Proc. Roy. Soc. (London) A123, 134 (1929)

properties. This theory, however, provides no exact method for calculating the thermal conductivity of polyatomic molecules. The simple correction due to Eucken appears to be applicable for cases where rapid equilibration of external and internal degrees of freedom occurs. Lambert and Rowlinson, ${ }^{7}$ from ultrasonic despersion, give values for the relaxation times in methane of the order of $10^{-7}$ second even to temperatures as high as $600^{\circ} \mathrm{K}$. The implication that thousands of collisions are necessary for equilibrium between external and internal degrees of freedom is sufficient to preclude any calculation of the thermal conductivity by the method of Eucken.

Ethane, a nonspherical molecule, presents a new problem, since we may justifiably inquire whether the manner of operation of the forces is the same for equilibrium and transport phenomena. The second virial coefficient of ethane is substantially negative even beyond $500^{\circ} \mathrm{K}$ (cf. A, $\mathrm{CH}_{4}$ ) implying strong intermolecular attractions; this fact manifests itself in a fairly strong dependence of the potential on large separations and we might not be surprised, therefore, that if a single set of parameters fails to reproduce both $B(T)$ and viscosity, that the set of parameters depending on virial-coefficient data has the larger value of $r_{m}$. These remarks describe the results included for ethane in Table I.

Our values for the viscosity of argon agree very well with those previously reported. Table II contains our results, values calculated from the potential parameters and some selected comparisons.

It is unsuitable to judge the usefulness of a potential by comparison with the principal property employed to gain the potential parameters. From Tables III and IV it becomes clear that the Exp: 6 potential is adequate over the range of comparison. The difficulties mentioned by Mason and Rice ${ }^{3}$ for the high-temperature viscosity of argon remain in our presentation, and their suggestion that the experimental values are low seems completely reasonable. For argon, therefore, our results serve only to justify the work of earlier authors.

${ }^{7}$ J. D. Lambert and J. S. Rowlinson, Proc. Roy. Soc (London) A204, 424 (1950). 
TABLE IV. Coefficients of self-diffusion for argon and methane using potential parameters from viscosity.

\begin{tabular}{|c|c|c|c|c|}
\hline Substance & $T^{\circ} \mathrm{K}$ & $\begin{array}{c}D_{11} \mathrm{~cm}^{2}-\mathrm{sec}^{-1} \\
\text { Calc. } \\
\text { (present work) }\end{array}$ & $\mathrm{Calc}^{\mathrm{a}}$ & $\mathrm{Obs}^{\mathrm{b}}$ \\
\hline A & $\begin{array}{r}77.7 \\
90.2 \\
194.7 \\
273.2 \\
295.2 \\
353.2\end{array}$ & $\begin{array}{l}0.0134 \\
0.0181 \\
0.0825 \\
0.155 \\
0.178 \\
0.248\end{array}$ & $\begin{array}{l}0.0134 \\
0.0181 \\
0.0824 \\
0.155 \\
0.178 \\
0.247\end{array}$ & $\begin{array}{l}0.0134 \\
0.0180 \\
0.0830 \\
0.156 \\
0.178 \\
0.249\end{array}$ \\
\hline $\mathrm{CH}_{4}$ & $\begin{array}{r}90.2 \\
194.7 \\
273.2 \\
298.2 \\
353.2\end{array}$ & $\begin{array}{l}0.0217 \\
0.100 \\
0.193 \\
0.227 \\
0.310\end{array}$ & $\begin{array}{l}0.0216 \\
0.100 \\
0.192 \\
0.226 \\
0.308\end{array}$ & $\begin{array}{l}0.0266 \\
0.0992 \\
0.206 \\
0.240 \\
0.318\end{array}$ \\
\hline
\end{tabular}

a M. P. Madan, J. Chem. Phys. 23, 763 (1955), from thermal diffusion. b E. B. Winn, Phys. Rev. 80, 1024 (1950).

Our experimental results for the viscosity of methane are on the average about $2 \%$ higher than previously reported values and do not show the unusually strong dependence on temperature reported by Trautz for

TABLE V. Comparison of observed viscosities of methane and ethane with those calculated for the Exp:6 potential.

\begin{tabular}{|c|c|c|c|c|c|c|}
\hline \multirow[b]{3}{*}{$T^{\circ} \mathrm{K}$} & \multicolumn{5}{|c|}{$10^{7} \eta \mathrm{g}-\mathrm{cm}^{-1}-\mathrm{sec}^{-1}$} & \multirow[b]{3}{*}{ Obs } \\
\hline & \multicolumn{3}{|c|}{ Methane } & \multicolumn{2}{|c|}{ Ethane } & \\
\hline & Obs & Calc & Obs & Obs & Caic & \\
\hline 210.7 & 810 & 815 & & & & \multirow{4}{*}{$\begin{array}{l}851 \\
909 \\
929\end{array}$} \\
\hline 250.1 & 967 & 960 & & 795 & 801 & \\
\hline 273.16 & 1031 & 1038 & $1022^{\mathrm{B}}$ & 869 & 873 & \\
\hline 292.7 & 1103. & 1104 & $1087^{a}$ & 930 & 930 & \\
\hline 300.7 & 1125 & 1128 & & 950 & 954 & \\
\hline 308.2 & 1155 & 1152 & $1112^{\mathrm{b}}$ & 970 & 975 & \\
\hline 320.7 & 1189 & 1193 & $\begin{array}{l}1175^{\mathrm{a}} \\
1150^{\mathrm{b}}\end{array}$ & 1010 & 1013 & $\begin{array}{r}990^{\circ} \\
1000^{\mathrm{b}}\end{array}$ \\
\hline 328.7 & 1220 & 1218 & $1206^{b}$ & 1035 & 1034 & $1034^{\mathrm{d}}$ \\
\hline 337.3 & 1253 & 1248 & $1238^{b}$ & 1064 & 1060 & \\
\hline 351.1 & 1281 & 1285 & & 1101 & 1098 & $1096^{b}$ \\
\hline 363.1 & 1322 & 1321 & & 1127 & 1132 & \\
\hline 373.2 & 1355 & 1353 & $1331^{\mathrm{a}}$ & 1155 & 1158 & $1142^{\mathrm{c}}$ \\
\hline 387.9 & 1391 & 1395 & & 1204 & 1200 & $\begin{array}{l}1167^{\mathrm{d}} \\
1245^{\mathrm{d}}\end{array}$ \\
\hline 394.4 & 1419 & 1423 & & 1230 & 1225 & \\
\hline 407.2 & 1449 & 1452 & & 1254 & 1251 & \\
\hline 424.4 & 1506 & 1503 & $1474^{\mathrm{a}}$ & 1289 & 1295 & $1278^{\mathrm{e}}$ \\
\hline 439.9 & 1541 & 1546 & & 1341 & 1335 & \\
\hline 451.6 & 1574 & 1578 & & 1372 & 1367 & \\
\hline 459.4 & 1594 & 1600 & & 1390 & 1387 & \\
\hline 473.16 & 1635 & 1638 & $1603^{a}$ & 1418 & 1422 & $1408^{\circ}$ \\
\hline
\end{tabular}

a M. Trautz and R. Zink, Ann. Physik 7, 427 (1930).

b J. D. Lambert et al., Proc. Roy. Soc. (London) A231, 280 (1955).

c M. Trautz and K. G. Sorg, Ann. Physik 10, 81 (1931).

d T. Titani, Bull. Chem. Soc. Japan 5, 98 (1930). temperatures higher than $400^{\circ} \mathrm{K}$. The rather limited data of Lambert et al. are about 3\% lower than our values but also fail to show the strong temperature dependence reported by Trautz (cf. Table V); our results are more nearly linear.

The coefficients of self-diffusion agree reasonably well with experimental values and very well with the previous results of Madan obtained from thermal diffusion. In a manner similar to argon, our values tend whenever different to be only slightly better than Madan's.

Uniformly good agreement is obtained for the calculated and observed values of $B(T)$ over the range of experimental measurement.

For ethane our representation fails. Two sets of parameters are required and this reduces the evaluation of $\gamma_{m}, \epsilon$, and $\alpha$ to an exercise in curve fitting. In some senses this is disappointing, but it seems to indicate quite strongly that the Chapman-Enskog formalism in conjunction with a potential of the form of an Exp: 6 cannot be expected to represent a molecule whose geometry and presumably, therefore, force field is nonspherical.

Experimentally, our results for ethane lie some 2\% lower than the values of Titani but 1-2\% higher than those of Trautz and Sorg and of Lambert, cf. Table V. The slope of our plotted data $(\eta v S T)$ is in good agreement with all previous investigations, although Titani's data appear to have a somewhat larger slope at higher temperatures.

\section{SUMMARY}

For the spherically symmetric molecule argon, we have used a three-parameter Exp: 6 potential to present the equilibrium and transport properties with a high degree of success. For methane essentially the same result is obtained, but for ethane, which deviates from spherical symmetry, a single set of parameters was unsuccessful in reproducing both sets of properties. We take this latter case to be additional confirmation for the suggestion of Mason and Rice ${ }^{3}$ that the assumptions of central forces and elastic collisions lack justification for most real gases.

Experimentally we have obtained values for the viscosities of argon, methane, and ethane from $c a$ $210^{\circ} \mathrm{K}$ to $c a 475^{\circ} \mathrm{K}$. Our results are within a few percent of previous investigations, and for ethane represent values which are nearly the average of previous results. 